\title{
Cyclic alternating pattern in normal children aged 12 to 24 months
}

\author{
Gabriela Rodrigues Alves' , Agostinho Rosa², \\ Magneide Brito', Marcia Pradella-Hallinan', Sergio Tufik
}

\begin{abstract}
Objective: The aim of this study is to complement existing data on the expression and characteristics of cyclic alternating pattern (CAP) in children, specifically in the 12 to 24 month age bracket. Method: Descriptive study. Settings: a university pediatric sleep laboratory. Participants: Twelve normal and healthy subjects ( 6 girls and 6 boys, mean age 18.9 4.72 months; range 12-24 months underwent a standard polysomnography night recording in our pediatric sleep laboratory. Sleep stages and CAP were analyzed according to standard international rules. Results: CAP rate found in children of 12 to 24 months of age was $(25.78 \pm 10.18 \%)$ and it is characterized by a linear increase of $2 \%$ per month, from $12 \%$ at 12 months reaching $35 \%$ at 24 months. With coefficient of determination $\mathrm{R}^{2}$ of 0.91 . The duration of $A$ phases was $6.93 \pm 1.06$ seconds, and $B$ phases was found to last $21.44 \pm 2.31$ seconds. The number of CAP cycles was $173.25 \pm 73.85$ with an average index per hour of $33.55 \pm 14.61$. The number of CAP sequences reached $25.25 \pm 9.55$ per recording. CAP rate for the different type of A phases are $(21.83 \pm 9.68 \%)$, for $A 1$, $(2.43 \pm 2.30 \%)$ for A3 and $(1.67 \pm 1.11 \%)$ for A2. Conclusion: Our study provides normative data on CAP in a group of young children (12 to 24 months). The most salient result of this study is the strong correlation of CAP rate of $2 \%$ per month in this age group.
\end{abstract}

Key words: cyclic alternating pattern, children, sleep.

\section{Padrão alternante cíclico em crianças normais de 12 a 24 meses}

\section{Correspondence}

Gabriela Rodrigues Alves Instituto do Sono, Departamento de Psicobiologia

Rua Marselhesa $500 / 14^{\circ}$ andar 04020-060 São Paulo SP - Brasil

E-mail: gabriela@psicobio.epm.br

Received 5 January 2010

Received in final form 16 April 2010 Accepted 26 April 2010

\section{RESUMO}

Objetivo: $O$ objetivo deste estudo é complementar os dados normativos sobre a expressão e as características do padrão alternante cíclico (CAP) em crianças, especificamente na faixa etária de 12 para 24 meses. Método: Estudo descritivo. Participantes: Doze indivíduos normais e saudáveis ( 6 meninas e 6 meninos, entre 12-24 meses de idade (média de $18,9 \pm 4,72$ meses), foram submetidos a uma noite de gravação de polissonografia em nosso laboratório de sono pediátrico. As fases do sono e CAP foram analisados de acordo com padrão e normas internacionais. Resultados: A taxa máxima encontrada em crianças de 12 a 24 meses de idade foi de $(25,78 \% \pm 10,18)$ e é caracterizada por um aumento linear de $2 \%$ ao mês, a partir de $12 \%$ em 12 meses atingindo $35 \%$ em 24 meses de idade. A duração da fase $A$ foi de $6,93 \pm 1,06$ segundos, e nas fases $B$ foi encontrado a média de $21,44 \pm 2,31$ segundos. O número de ciclos CAP foi $173,25 \pm 73,85$, com um índice médio

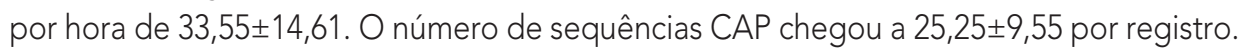
Os índices dos subtipos de fases A foram $(21,83 \% \pm 9,68)$, para a A1, $(2,43 \% \pm 2,30)$ para a A3 e $(1,67 \% \pm 1,11)$ para A2. Conclusão: Nosso estudo fornece dados normativos sobre CAP em um grupo de crianças (12 a 24 meses de idade). O resultado mais saliente deste estudo é a forte correlação entre taxa do CAP e idade, mostrando que a cada mês ocorreu o aumento de $2 \%$.

Palavras-chave: padrão alternante cíclico, crianças, sono.

'Department of Psychobiology, Federal University of São Paulo, São Paulo SP, Brazil; ${ }^{2}$ Evolutionary Systems and Biomedical Engineering Lab, ISR-IST, Lisbon, Portugal. 
A limited number of studies have been conducted in order to analyse normal sleep architecture in children and assess more specific patterns such as cyclic alternating pattern (CAP).

It is known that as weeks and months of life go by EEG pattern changes. The graphic physiological characteristic of sleep evolves thereby enabling non rapid eye movements (NREM) stages to be identified. We believe that by only assessing sleep macrostructure, we can lose important data regarding the maturation of electroencephalogram patterns during sleep. We believe that CAP studies can be a crucial tool to evaluate the instability, sleep fragmentation, maturation and EEG development in children.

CAP analysis and other criteria related to arousal classification are necessary where they set out to quantify the ratio between sleep fragmentation and its neurocognitive consequences. A child with sleep disorders such periodic leg movements, as apnea and snoring, different from adults, do not present significant alterations in sleep macrostructure.

Cyclic alternating pattern is a normal physiological electroencephalogram pattern which is commonly observed in healthy subjects during NREM sleep ${ }^{1}$. It is characterized by periodical recurrence of phasic morphological patterns which are compounded by the alternation of activation phases (A phase) followed by inhibition phases (B phase) $)^{2}$.

Three main EEG A phase patterns were described: A1 subtype has a predominance of synchronized EEG activity. In the A3 subtype, the opposite situation revealing the predominance of EEG desynchronization can be found. The A2 subtype is represented by a combination of both A1 and A3 subtypes. These subtypes have different interpretations: A1 subtype is involved in the building up and maintenance of deep NREM sleep and can have a protective role for sleep continuity; A2 and A3 can be involved in NREM activity and display the function of maintaining subject arousability ${ }^{2}$.

Few studies are found of CAP in childhood and youth, Bruni $^{3,4}$ described the default of CAP in pre school and school children, Lopes ${ }^{5}$ in peripubertal and Miano ${ }^{6}$ studied the CAP in infants from 1 to 4 months of age. There are no studies showing a consistent CAP pattern rate in the very young age range. In order to offer a comprehensive overview of CAP development in the first years of life, the aim of this study was to describe CAP pattern in children of 12 to 24 months of life. It is argued that such an approach can become a new tool to help further our understanding of normal sleep and its disorders within this age range.

\section{METHOD}

\section{Volunteers}

Following an announcement using standard media communication, nineteen parents of children aged be- tween 12 and 24 months (without sleep-related complaints), contacted the Sleep Institute (Sleep Laboratory of Psychobiology Department from Federal University of São Paulo, São Paulo SP - Brazil) with a view to participating in the study.

We applied the "Sleep Disturbance Scale for Children" which is a questionnaire which requires information on behaviour and general medical conditions such as diseases and use of medication. The second part involves scale items which indicate values from 1 to 5 for the frequency of each affirmation regarding sleep, such as before and during sleep behaviour, respiratory disorders and investigation of neurological disorders along with received medication.

Selected children had no sleep disorder and no severe diseases. All volunteers with history of prematurity and anoxia were excluded. No child took medication at the time of the study. All participants were required to follow sleep laboratory routine regarding good sleep habits one week before the study. By the day of the study, normal daily activities of the children were maintained.

Only 12 children (six boys and six girls) met the inclusion criteria. Parent or care giver signed the informed consent form for this study and adhesion to it was a voluntary act. The present study was approved by the Ethics Committee of the Federal University of São Paulo.

\section{Polysomnografic recordings (PSG)}

Sleep recordings ware performed in a standard laboratory setting of Sleep Institute's Psychobiology Department, UNIFESP. We endeavoured to maintain normal daily activities before sleep time including normal physical activities and alimentary habits. The recordings were conducted with a minimum duration of 7 hours. All children went to bed at their usual sleep time. The end of the recording occurred in the morning spontaneously. We performed subjective assessment of sleep quality by means of post-sleep questionnaires in which the parent or care giver attributed a value regarding his/her perception of how successful the night had been for the child in question.

All rooms had acoustic insulation to keep possible external noise under control. Ambient temperature ranged between $20^{\circ} \mathrm{C}$ to $23^{\circ} \mathrm{C}$. Children slept in separate beds from their parent or care giver in order to avoid any interference in the recording.

Recordings were performed and logged in a digital polysomnografic system (Alice Host, Respironics, Inc). EEG using the international 10/20 system to place electrodes in standardized scalp locations (C3-A/M2, C4-A/ M1, O1-A/M2, O2-A/M1), 2 for electrooculogram (right and left), 2 for electromyogram (chin and anterior tibial), and 2 for electrocardiogram as well as oronasal thermistors, nasal pressure cannula, microphone, thoracic and 
abdominal belts, and pulse oximetry. Each recording was exported into the European Data Format and the Somnologica (Flaga-Medcare, Reykjavik, Iceland) software was used to assess sleep and CAP.

\section{Criteria for sleep architecture classification and CAP}

Recordings were scored by the agreement of two experienced sleep investigators, based or Rechtschaffen and Kales $^{7}$ criteria. The arousal events were scored according to American Sleep Disorders Association ${ }^{8}$. Sleep macrostructure was scored based or conventional parameters such as sleep efficiency, TST (total sleep time), sleep onset latency (delay time from saying good night or lights out to the three consecutive epochs of stage 1 NREM sleep or any other sleep stage), total duration of sleep stages (1, 2, 3 and 4 NREM sleep) and REM sleep total duration.

CAP was classified visually based or the criteria described by Terzano et al. ${ }^{9}$. However some adaptation was needed regarding this age range for the subtypes classification (A1, A2 and A3), and some auxiliary EEG channels were used (O1-A/M2 or O2-A/M1) along with EMG and ECG. Due to the non occurrence of physiological alpha rhythms in the studied age range, we decided to use the most prevalent rhythm - theta (4-7 Hz) for CAP classification. We classified A1 subtype when theta rhythm was detected in the central channels and when no cardiorespiratory repercussion was observed or no concurrent increase in EMG was noted. We further classified this subtype when theta rhythm was detected in the central and occipital channels and when there was cardiorespiratory repercussion and/ or enhancement of EMG tone A2 or A3 subtypes, depending on their duration.

\section{Statistical analysis}

The Mann-Whitney U test was used for identifying sex differences. Regarding the three subtypes of CAP phases, we reported the absolute number, relative percentage and mean duration in seconds. We also assessed the frequency per hour (index) and the mean duration of CAP phases in the different NREM sleep stages.

Two-dimensional plotting of the interval (in seconds) distribution of $\mathrm{A} 1$ and $\mathrm{A} 2+\mathrm{A} 3$ phase was also obtained in order to establish the mean interval values and to assess whether a preferential distribution can be observed from different distributions. Linear regression was performed to model the relationship between CAP rate and Age. The software system STATISTICA (StatSoft, Inc. 2004, version 6) was used for statistical analysis.

\section{RESULTS}

The mean age of the study group was $18.9 \pm 4.72$ months. Sleep quality in the laboratory was considered satisfactory when evaluated by parent or care giver in the morning following the polysomnographic recording.

The mean total sleep time was $416.0 \pm 40.49$ minutes and the mean of stage 1 NREM sleep was $3.99 \pm 2.82$; stage 2 was $37.39 \pm 8.43$. The sum of the mean values for stages 3 and 4 was $33.64 \pm 9.01$ and REM sleep produced $24.78 \pm 5.06$ minutes (Table 1).

The mean CAP rate found is $(25.78 \% \pm 10.18)$ at 12 months its value is $12 \%$ and reaching $35 \%$ at 24 months. The CAP rate was found by linear regression to exhibit a gradual increase of $2 \%$ per month with age [regression curve is CAP (\%); $y=1.94722 \times$ (age in months) -10.734 ]. (Figure) and the Pearson's coefficient of determination $\mathrm{r}^{2}$ is 0.9092 with $\mathrm{p}<0.001$.

CAP analysis revealed that the duration of A phases was $6.93 \pm 1.06$ seconds while B phases scored $21.44 \pm 2.31$ seconds. The number of CAP cycles was $173.33 \pm 73.80$ and the mean index of CAP cycles per hour in the pres-

Table 1. Sleep parameters in 12 children.

\begin{tabular}{lc}
\hline TTS (min.) & $416.0 \pm 40.49$ \\
\% Sleep efficiency (TS/TTR) & $86.14 \pm 5.87$ \\
Sleep onset latency (min.) & $33.13 \pm 38.55$ \\
Sleep REM latency (min.) & $33.13 \pm 38.55$ \\
Arousal & $66.0 \pm 26.46$ \\
Arousal index /h & $9.38 \pm 3.56$ \\
\% S 1 & $3.99 \pm 2.82$ \\
\% S 2 & $37.39 \pm 8.43$ \\
\% S 3 and 4 & $33.64 \pm 9.01$ \\
\% REM Sleep & $24.78 \pm 5.06$ \\
\hline
\end{tabular}

TTS: total sleep time; TTR: total recording time; REM: rapid eye movements.

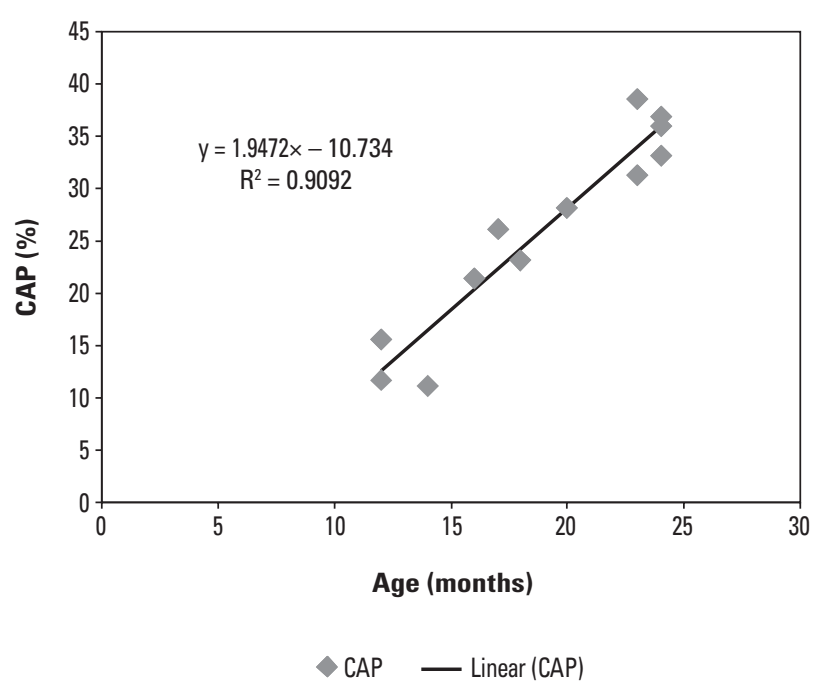

Figure. Linear regression: CAP rate related to age. 
Table 2. Relationship between CAP, age and gender.

\begin{tabular}{cccccc}
\hline Gender & Months & CAP Rate $\%$ & Gender & Months & CAP Rate $\%$ \\
\hline F & 12 & 9.5 & M & 12 & 15.6 \\
F & 14 & 9.5 & M & 16 & 21.5 \\
F & 17 & 26.1 & M & 20 & 28.2 \\
F & 18 & 23.2 & M & 23 & 31.3 \\
F & 23 & 38.6 & M & 24 & 36.0 \\
F & 24 & 36.8 & M & 24 & 33.1 \\
Mean-SD & $18.00 \pm 4.77$ & $23.95 \pm 12.67$ & Mean-SD & $19.83 \pm 4.92$ & $24.72 \pm 9.99$ \\
\hline
\end{tabular}

CAP: cyclic alternating pattern; SD: standard deviation.

ent study was $33.55 \pm 14.61$. The total number of A phases is (2080), A1 is the most dominant (1805), followed by A3 (160) and (115) A2. The CAP rate was $25.78 \pm 10.18 \%$ and phase A1 subtype had an higher contribution 21.83 9.68\%, then phase A3 $2.43 \pm 2.30 \%$ and phase A2 with $1.67 \pm 1.11 \%$. We did not find significant differences in CAP rate related to gender (Table 2).

CAP rate in stage 1 NREM sleep was $6.88 \pm 10.41$, in stage 2 this was $14.39 \pm 8.67 ; 39.29 \pm 23.37$ in stage 3 and $47.87 \pm 18.73$ in stage 4 . We observed that CAP rate increases as sleep becomes deeper.

The A phases duration according to sleep stages were distributed as follows: stage 1 NREM sleep was $7.56 \pm 1.77$ seconds; stage 2 was $6.27 \pm 1.73$ seconds, in stages 3 and 4 was $11.30 \pm 3.14$ seconds.

A high percentage of A1 subtype was observed in sleep stage $4(45.88 \pm 19.01 \%)$ when compared to stage 1 (8.72 $\pm 7.01 \%)$.

Table 3 shows a comprehensive overview of CAP parameters.

\section{DISCUSSION}

Our study is to our knowledge the first one to analyse CAP normative data in the 12 to 24 month of life age range.

Some adaptation was needed regarding this age range for the subtypes classification (A1, A2 and A3), In the present study we considered the need of using auxiliary channels besides other EEG channels (O1-A2, O2-A1), EMG submental, ECG and respiratory frequency due to the absence of alpha rhythm in EEG. Theta rhythm was used to classify A1, A2 and A3 subtypes.

Parrino ${ }^{10}$ initially hypothesized that CAP rate shows a U-shaped curve throughout the life cycle, and assumed that by birth time, CAP rate is $100 \%$. The curve showed a nadir of $38 \%$ in young adults (20 to 39 years old) and an increased rate higher than $60 \%$ for elderly population. Normative studies in children do not reinforce this hypothesis, where the \% CAP rate in children of age pre school ${ }^{5}$ is $(25.93+13.51 \%)$, up at school age to ${ }^{6}$
Table 3. CAP parameters.

\begin{tabular}{|c|c|c|}
\hline Data & Description & Mean- SD \\
\hline Age month & in months & $18.92 \pm 4.72$ \\
\hline CAP $\%$ & CAP rate/index in \% & $25.78 \pm 10.18$ \\
\hline A Sec & $\begin{array}{l}\text { Phase A mean } \\
\text { duration in seconds }\end{array}$ & $6.93 \pm 1.06$ \\
\hline B Sec & $\begin{array}{l}\text { Phase B mean } \\
\text { duration in seconds }\end{array}$ & $21.44 \pm 2.31$ \\
\hline Cap cycles \# & Number of Cap cycles & $173.33 \pm 73.80$ \\
\hline Cap index cyc/h & Cap index in Cycles/hour & $33.55 \pm 14.61$ \\
\hline nseq \# & $\begin{array}{l}\text { number of CAP } \\
\text { sequences }\end{array}$ & $25.25 \pm 9.55$ \\
\hline Cycles in seq \# & $\begin{array}{l}\text { number of cycles in } \\
\text { cap sequences }\end{array}$ & $161.33 \pm 74.09$ \\
\hline CAP A $1 \%$ & A1 CAP rate in $\%$ & $21.83 \pm 9.68$ \\
\hline CAP A2 \% & A2 CAP rate in $\%$ & $1.67 \pm 1.11$ \\
\hline CAP A3 \% & A3 CAP rate in $\%$ & $2.43 \pm 2.30$ \\
\hline S1 \% & CAP rate in $\mathrm{S} 1$ in \% & $11.79 \pm 11.47$ \\
\hline S2\% & CAP rate in $\mathrm{S} 2$ in \% & $14.39 \pm 8.68$ \\
\hline S3 \% & CAP rate in $\mathrm{S3}$ in \% & $39.29 \pm 23.37$ \\
\hline S4 \% & CAP rate in $\mathrm{S} 4$ in \% & $47.87 \pm 18.74$ \\
\hline A1S1 \% & $\mathrm{A} 1$ CAP rate in $\mathrm{S} 1$ in $\%$ & $8.72 \pm 7.01$ \\
\hline A1S2 \% & $\mathrm{A} 1$ CAP rate in $\mathrm{S} 2$ in $\%$ & $8.87 \pm 7.44$ \\
\hline A1S3 \% & $\mathrm{A} 1$ CAP rate in $\mathrm{S} 3$ in $\%$ & $37.64 \pm 23.95$ \\
\hline A1S4 \% & A1 CAP rate in $\mathrm{S} 4$ in \% & $45.88 \pm 19.01$ \\
\hline A2S1 \% & $\mathrm{A} 2$ CAP rate in $\mathrm{S} 1$ in $\%$ & $1.20 \pm 0.14$ \\
\hline A2S2 \% & A2 CAP rate in $\mathrm{S} 2$ in $\%$ & $1.93 \pm 1.32$ \\
\hline A2S3 \% & A2 CAP rate in $\mathrm{S} 3$ in $\%$ & $7.00 \pm 6.93$ \\
\hline A2S4 \% & $\mathrm{A} 2$ CAP rate in $\mathrm{S} 4$ in $\%$ & $1.79 \pm 1.09$ \\
\hline A3S1 \% & $\mathrm{A} 3$ CAP rate in $\mathrm{S} 1$ in $\%$ & $11.10 \pm 5.47$ \\
\hline A3S2 \% & A3 CAP rate in $\mathrm{S} 2$ in \% & $3.78 \pm 3.19$ \\
\hline A3S3 \% & $\mathrm{A} 3$ CAP rate in $\mathrm{S} 3$ in $\%$ & $2.95 \pm 1.48$ \\
\hline A3S4 \% & A3 CAP rate in S4 in \% & $0.64 \pm 0.57$ \\
\hline CAP time min & Time in CAP in Minutes & $80.69 \pm 31.95$ \\
\hline \#A & Number of $A$ & 2080 \\
\hline \#A1 & Number of A1 & 1805 \\
\hline \#A2 & Number of A 2 & 115 \\
\hline \#A3 & Number of A 3 & 160 \\
\hline \#AS1 & Number of $A$ in Stage 1 & 32 \\
\hline \#AS2 & Number of $A$ in Stage 2 & 610 \\
\hline \#AS3 & Number of A in Stage 3 & 116 \\
\hline \#AS4 & Number of $A$ in Stage 4 & 1322 \\
\hline $\mathrm{A} 1 / \mathrm{A} \%$ & $\mathrm{~A} 1 \%$ & 86.78 \\
\hline A2/A \% & $\mathrm{A} 2 \%$ & 5.53 \\
\hline $\mathrm{A} 3 / \mathrm{A} \%$ & $\mathrm{~A} 3 \%$ & 7.69 \\
\hline
\end{tabular}

SD: standard deviation; CAP: cyclic alternation pattern. 
$(33.43+5.27 \%)$ and reaches a peak $(62.1+10.8 \%)$ peripubertal children ${ }^{7}$, these data suggest that the CAP rate tends to increase from a few months after birth until puberty. Our study and our data follow the same trend of available normative studies in children, showing that the CAP rate in children of 12 to 24 months of life is between the younger and older ones.

Normative studies of the pattern of CAP in healthy newborns and infants are not available yet. A recent research using 3-hour video-electroencephalographic EEGpolygraphic recording, analysis concluding that CAP is not possible before 46 weeks of life due to lack of sleep grafoelements such as sleep spindles and delta when the pace is during quiet sleep (QS) demonstrating in posterior regions, different patterns of the CAP where normally involve the central and frontal ${ }^{9}$. Given the lack of data on the 6-11 month and 25-35 month age brackets, additional studies are necessary to fill the gaps. Nevertheless all these studies have been performed with a limited number of data, so their conclusions shell be confirmed and reinforced with further and larger studies.

It was seen that in children 12 to 24 months have greater expression in terms of subtype A1 of CAP (86.78\%) in different stages of sleep, also showing greater quantity during stage 4 (63.56\%) of sleep NREM (deep sleep). Our data and studies in children at school age, reported an increase in the percentage of A1 (84.45\%), strengthen the hipothesis that the CAP can be a marker of thalamocortical interactions and maturation of brain activity.

Ferri ${ }^{11}$ reported that the slow components of CAP (A1) could be considered as the expression of cortical synchronizing mechanisms during sleep of NREM. The slow wave sleep may promote the formation of thalamocortical networks providing endogenous neural signals with repetitive and synchronized activity. The gradual maturation of thalamocortical networks could drive the gradual emergence of a pattern of alternating slow EEG activity. The obtained results reinforce the hypothesis that CAP rate increases from the first year of life until puberty. Our results attempt to bridge the existing gap in the literature by providing more data regarding CAP rate curve in the studied age range.

\section{REFERENCES}

1. Terzano MG, Mancia D, Salati MR, et al. The cyclic alternating pattern as a physiologic component of normal NREM sleep. Sleep 1985;8:137-145.

2. Terzano MG, Parrino L. Origin and significance of the cyclic alternating pattern (CAP). Sleep Med Rev 2000;4:101-123.

3. Bruni O, Ferri R, Miano S, et al. Sleep cyclic alternating pattern in normal preschool-aged children. Sleep 2005;28:220-230.

4. Bruni O, Ferri R, Miano S, et al. Sleep cyclic alternating pattern in normal school-age children. Clin Neurophysiol 2002;113:1806-1814.

5. Lopes MC, Rosa A, Roizenblatt S, et al. Cyclic alternating pattern in peripubertal children. Sleep 2005;28:215-219.

6. Miano S, PiaVilla M, Blanco D, et al. Development of nremsleep instabilitycontinuity (cyclic alternating pattern) in healthy term infants aged 1 to 4 months. Sleep 2009;32:83-90.

7. Rechtschaffen A, Kales A. Manual of standardized terminology: techniques and scoring system for sleep stages of human subjects. Los Angeles: UCLA Brain Information Service / Brain Research Institute; 1968.

8. EEG Arousals: scoring rules and examples. An American Sleep Disorders Association Report. Sleep 1992;15:173-184.

9. Terzano MG, Parrino L, Smerieri A, et al. Consensus report: atlas, rules, and recording techniques for the scoring of cyclic alternating pattern (CAP) in human sleep. Sleep Med 2001;2:537-553.

10. Parrino L, Boselli M, Spaggiari MC, Smerieri A, Terzano MG. Cyclic alternating pattern (CAP) in normal sleep: polysomnographic parameters in different age groups. Electroencephalogr Clin Neurophysiol 1998;107:439-450.

11. Ferri R, Bruni O, Miano S, Terzano MG. Topographic mapping of the spectral components of the cyclic alternating pattern (CAP). Sleep Med 2005;6: 29-36. 